\title{
Review of Kremplewska's Life as Insinuation
}

Katarzyna Kremplewska. 2019. Life as Insinuation: George Santayana's Hermeneutics of Finite Life and Human Self. Albany, NY: SUNY Press.

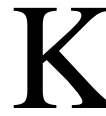

atarzyna Kremplewska's book Life as Insinuation: George Santayana's Hermeneutics of Finite Life and Human Self examines Santayana's conception of selfhood, making insightful comparisons with relevant European thinkers and yielding interpretations of important concepts such as freedom and tragedy. This work, like Daniel Moreno's Santayana the Philosopher: Philosophy as a Form of Life (2009; 2015), presents Santayana's philosophy as an attempt "to prevent humans from turning into lunatics" (Kremplewska 111). But Kremplewska's work is distinct in its emphasis on selfhood, indicating the richness of Santayana's philosophy and the originality of Kremplewska's approach, which displays impressive knowledge of both primary and secondary sources. Her work should influence international conversations about the meaning and importance of Santayana's philosophy, demonstrating its relevance to the Continental tradition and to an enlarged set of issues ranging across traditions.

Kremplewska claims that Santayana's theory of selfhood is central to his philosophy of life, which she calls contemplative vitalism. Both are understood in terms of Santayana's nonreductive ontology, inoculating them against dualistic conceptions and making "the reality of human life irreducible to the relations of power" (Kremplewska xiv). Kremplewska's interpretation stands apart from those that present Santayana as dissolving the self, reducing it to the vital organizing principle of a material being (psyche), or positing an immutable "kernel." She describes a dynamic self that unites material and spiritual aspects, achieving integrity in an ongoing interpretive process. The first three chapters present Santayana's theory of selfhood, including what is at stake in such theorizing (living well and sanely), the significance of the self to Santayana's philosophy (theory of selfhood as translating ontology into a way of living), and what counts as the good life (freedom through finitude and transcendence).

What is at stake in understanding the self, is a sane and livable orientation to the world. A conception of selfhood reflects an understanding of reality, which has a bearing on how well we live. Drawing on Charles Taylor's work, the book begins with a survey of European conceptions of selfhood. For Augustine, introspection was checked by the reality of God, which limited the excesses of subjectivity. Aristotle's relational self-cultivated excellent action and practical wisdom, culminating in contemplation. But Cartesianism, lacking Augustine's antidote to the self and Aristotle's naturalism, resulted in unrestrained philosophical egotism, opened a chasm between self and world, and rendered reason instrumental. While many subsequent responses to Cartesianism failed to curb the ego or mend the self-world split, Kremplewska sees "[a] breakthrough in thinking about subjectivity [with the appearance of] the idea of stream of consciousness" (Kremplewska 12) as in the thought of William James, Edmund Husserl, and Henri Bergson. 
Their consideration of tensions between subjectivity and factuality and between finitude and freedom greatly influenced Santayana as he challenged egotistic illusions and rampant subjectivity that marked modernity.

Santayana's conception of selfhood is significant because it translates his ontology into terms directly relevant to human living. His ontology rejected Cartesianism and Hegelianism and their logic - a logic entailing a hegemonic self and insisting that self be persistent, autonomous, and identical to ego or else dissolved altogether. Santayana's ontology united self and world and tamed the ego without sacrificing consciousness as do philosophies of will to power. Kremplewska points out that Santayana's ontological distinctions - the realms of essence, matter, truth, and spirit - account for an intelligible reality, objective truth, the possibility of human freedom through spirituality, the value of imagination in itself, and the potential of essences to counter superstitious idealism. This ontology allowed him to synthesize traditional oppositions, acknowledging both spirituality and materialism, and to suppress ego while articulating a conception of individual selfhood.

According to Kremplewska, Santayana conceived an aporetic self, which includes seemingly incompatible elements and eludes any fixed and final description. The aporias of self are articulated in Santayana's terms of psyche, the vital pattern of a material organism that preserves its life, and spirit, impotent consciousness or intuition of essences (qualities and forms in themselves). The first aporia arises from the contrast of spirit's disinterested awareness of essences as immediate, actual, and infinite with psyche's experience of the flow of future into past involving memory and anticipation. The second aporia arises from the contrast of the "Cartesian illusion of spiritual independence" (Kremplewska 41) with the fact of psyche's material nature.

These two subjective experiences of conflicting elements set philosophical challenges; and explanations of the aporias reveal the nature of selfhood. They are ignored by conceptions of a fixed, unitary ego, which aspires to master the world but proceeds by imposing illusions: Egotistic conceptions ignore the impossibility of controlling an irrational material flux or surveying infinite essences; they ignore otherness, denying the complexity and relational aspect of selfhood. Santayana's ontology counters ego's illusions and acknowledges our suspension in ignorance between irrational matter and infinite essence. His materialism introduces an impersonal perspective without reducing all reality to matter. Matter is the realm of power, spirt of the free but impotent witness; and both are real. Acknowledging human finitude is necessary to restrain ego and maintain sanity.

Acknowledging ignorance and seeking to interpret the experience of the aporias without ego's illusions, reveals the hermeneutic self, which is "a triadic temporal structure . . . a psycho-spiritual unity with an irreducible first-person perspective" (Kremplewska 46). As a structure it unites material body, living organism, and consciousness; as temporal it is an ongoing process of translating psyche's material impulses into spirit's medium of essences and then into symbolic knowledge of the material realm. Freedom and integrity arise when the self understands its own nature, which is characterized by finitude and integration of body, psyche, and spirit in intelligent action. 
Spirit adds a dimension of interpretation and communication, transcending material existence. This does not deny the material genesis of the self (which includes the body and the psyche), but it can reverse the relation in terms of freedom. Awareness of essences - of the forms and patterns of existence - frees humans to articulate an autobiography that is not dictated solely by biology. This freedom has limits: the hermeneutic self remains aporetic, spirit remains impotent in the realm of matter, but this does not make transcendence unreal. For Santayana, living is transcendence: we come from a birth no one can remember moving to a death no one can experience; these limits of consciousness are the material events that living consciousness transcends. Birth, death, and the aporias of selfhood are inescapable reminders of finitude, which modify expectations, restrain ego, and discourage delusion.

The impotence of spirit may make its transcendence seem an unhelpful source of freedom; but Kremplewska contends that since Santayana begins his account with a dynamic unity, spirit "acquires a function in the context of this whole" (Kremplewska 64). If the self is a dynamic unity, the impotence of spirit is consistent with its "activating role in the process of life" provided that it never be regarded as distinct from the process (Kremplewska 65). Spirit's activating role can be observed in the efficacy of thinking, which Kremplewska understands as "no less material than spiritual ... a psycho-spiritual, interpretive way of exercising psychic power and expressing its nature" (Kremplewska 65, 67).

The dynamic unity of the self and of the ontological realms more broadly is key to contemplative vitalism, Kremplewska's interpretation of Santayana's philosophy of life. Just as the hermeneutic self unites spirit and psyche, the good life of contemplative vitalism unites spiritual and active life. In contemplative vitalism, spirit's ability to raise life above material relations of power makes possible freedom of intelligent action, freedom to become oneself (vital liberty), and the free life of the mind. Contemplation belongs to the "to the wider dynamics of an individual life" (Kremplewska 69), so that spirituality can bring a new quality to the dynamic unity of the self and influence active life. In contemplative vitalism, reason escapes the narrow constraints of instrumentality and enriches the immediate quality of human life.

The benefits of spirituality are explained further in Kremplewska's consideration of Santayana's metaphor of masks. Masks cover and uncover nature: they cover existences and, like essences, are a medium of understanding and intelligent interactions; they uncover nature by revealing our knowledge to be symbolic and relative to our concrete lives. Masks are the meaningful results of the hermeneutic process and a medium of self-understanding and social relations. Some are tempted to cling pathologically to a particular mask as a fixed fact; for example, when a dogma, ideology, or conventional role stifles spontaneity and personal growth. But we live more fully when we regard masks from a spiritual perspective as varying expressions of psyche that are immaterial and infinite. This allows us to regard them as possibilities for a self and the self as something to be negotiated. This provides "the margin of the freedom of authorship" of the self (Kremplewska 82). 
If a mask, as an expression of psyche, determines a role for a self to play, it remains for that self to play the role well or badly: The drama I enact is only partly dependent on the role I am given; there also is the immediate situation including other actors in the drama, the audience, the setting, the broader social circumstances. In my performance, I can enact my freedom. Kremplewska writes, "[e]lements of spiritual practice support the enactment of" the freedom of authorship because they cultivate the ability to suspend masks, to momentarily transcend the facts of our decisions and actions, and to remain open and attentive to possibilities (Kremplewska 82). This openness and attention, liberated from material concerns, "may become a discipline and an art capable of transmuting the whole performance of life" (Kremplewska 83). This spirituality is not a final goal but a phase of living. Living authentically is no permanent state or final accomplishment; Kremplewska characterizes it as "a quality of expression" and "a fragile equilibrium, which depends on a sustained engagement with life" (Kremplewska 84). This equilibrium indicates an honest self-free from delusion and free to be itself.

Chapters 4 and 5 compare Santayana with Henri Bergson and with Martin Heidegger, which enhance understanding of significant concepts in Santayana's conception of selfhood by placing them in broader philosophical contexts. The chapters appear to reflect the two aporias of the self. Chapter 4's concern with temporality recalls the first aporia that arises from spirit's eternal perspective and psyche's experience of sentimental time; Chapter 5's consideration of the relation of self and world, or of spirit and matter, recalls the second aporia that arises from spirit's sense of control and the fact of psyche's materiality.

Santayana and Bergson shared a concern for freedom from the mechanical repetition of material forces, and both thought that spirit and our experience of temporality provide opportunities for freedom. Their similarities converge in Bergson's idea of insinuation. Bergson thought of life as continual insinuation or infiltration of one thing by some other thing; and it was through insinuation that spirit could win freedom from material necessity. Past events as memory insinuate themselves into perception of the present, allowing the self to transcend and make sense of the present. In this way, spirit insinuates itself into the material flux. In this hermeneutic insinuation, consciousness draws on the past by using memory to perceive the present and by using established bodily affects and reactions to respond to the present: The past is "resurrect[ed] in the costume of the present moment" (Kremplewska 102). This "paradoxical new repetition" provides a margin of freedom from a mechanical repetition and materiality; the past is a source of liberation for the self and is essential to human agency.

Kremplewska writes that Bergson's "vision of freedom starts with the very fact that we endure, have a history, and accumulate memories like a snowball, to re-live them creatively myriads of times when thinking and acting" (Kremplewska 103). She explains that Bergson understood finitude as the irrevocability of the past and then articulated how it made human freedom possible; these ideas are significantly similar to those of Santayana who thought human freedom depends on both spirituality and limited psychic experience of time. 
In the next chapter, Kremplewska imagines a debate between Santayana and Heidegger based on Santayana's reading of Heidegger's Sein und Zeit, as documented in George Santayana's Marginalia (MARG Book 1). Kremplewska finds "strategic affinities among large concepts and ideas" (Kremplewska 122) as when Santayana indicated rough analogues of his notions of animal faith, realm of essence, and intuition in Heidegger's work, and when he understood Heidegger's Dasein as "spirit incarnate." Both thinkers rejected a Cartesian quest for certainty and asked, in Kremplewska's words, "What do the facts of the centrality of awareness and thinking to this particular form of life tell us about its being/nature?" (Kremplewska 115).

Comparing Santayana and Heidegger's ideas aids understanding of the aporetic self and the dangers it faces. Because self-understanding is always in the making, it involves a risk of failure and tempts abandonment of the vital interpretative task. On Heidegger's view, Dasein tends to falsely understand itself as a thing in the world or a fixed and disembodied self. But self always misses itself in its living being; what it perceives always comes too late to fully identify the dynamic self. This attunement, in Heidegger's terminology, is, thought Santayana, similar to "spirit incarnate" which involves a never-fully understood material psyche and a perceived mask or essence which can never reveal the dynamic psyche. This situation can tempt one to retreat from life and assume a fixed identity, thereby destroying the equilibrium of the honest self. This, for Santayana, is spiritual distraction and, for Heidegger, inauthentic being. Recognition of finitude can counter this and makes possible a fulfillment of life and a liberation of spirit from the distraction of false understanding and delusion.

More complex than the preceding two chapters, the sixth compares Santayana and Nietzsche, and it also surveys modern interpretations of tragedy and reads Shakespeare's Hamlet as an expression of secularized culture and subjectivized tragedy. The chapter relates and extends key ideas of the book by presenting Santayana's understanding of the tragic as integral to his criticism of egotism and his notion of an aporetic self.

The notion of tragedy changed with modern conceptions of the self. The ancient concern with fate is replaced by individual responsibility and a subjective understanding of tragedy. Nietzsche thought the emphasis on individuality devalued Dionysian heroism and tragic suffering in favor of Apollonian representation: the mask of convention and static selfhood obscured the fluidity of existence. Nietzsche responded with the idea of eternal return, which Kremplewska reads as "a metaphysical experiment in thinking . . . a conscious risk, a wager" (Kremplewska 168) played out in choosing a temporal perspective that foregoes what Santayana called sentimental time. Nietzsche thought this could liberate will, transcending accidental, individual being and modern subjectivity.

Santayana's criticism of Nietzsche does not, of course, take issue with rejecting modern subjectivity; rather Santayana thought Nietzsche's rejection remained adversely influenced by modern philosophy: The doctrine of the will to power, which reduced individuality to a play of forces, resulted in a "barbaric" philosophy, and carried on modern philosophy's rendering "self incapable of transcendence" (Kremplewska 165). For Santayana, Nietzsche's philosophy had two main 
harmful results: rejection of transcendence and embrace of instrumental reason. According to Kremplewska, Santayana read Nietzsche as replacing transcendence with "the spontaneity of the will and [transgression of] the boundaries of humanity" (Kremplewska 171), leaving no place for spirit, ideals, or disinterestedness, which make human freedom possible. For Santayana, Nietzsche's thought embodied instrumental reason, making thinking a means to survival and making truth whatever is useful for this (continuing German Idealism's attempt to eliminate the precariousness of life). "The polemic of Santayana with Nietzsche, then, was first and foremost an argument about the possibility and the necessity of spirituality" (Kremplewska 175).

Spirituality in a material world was central to Santayana's understanding of the tragic. Kremplewska writes, "The tragic aspect of existence may be traced in the discontinuities within the self, reflected in its aporetic status and fully revealed in the ontology of realms, where the self finds itself in a Pascalian suspension in-between 'two abysses of infinity and nothingness"' (Kremplewska 176). Conflicts between the human and the divine, facts and ideals, matter and spirit are tragic conflicts. Refection on the tragic brings out the significance of the aporetic self and of the recognition of finitude. The hermeneutic self neither denies tragedy with a conventional mask nor dissolves the self in a play of forces, but seeks sane equilibrium between freedom and necessity. The discussion of Shakespeare's Hamlet demonstrates how different conceptions of a unified self influence the experience and understanding of the tragic, and what this means for achieving a sane equilibrium. Shakespeare's work reflected Santayana's concern with how conceptions of the self influenced actual living.

The final chapter considers the political implications of Santayana's conception of selfhood and is a prospectus for further research into the social significance of Santayana's ideas. The chapter, the shortest in the book, is comparable to other, longer chapters in the variety of its insights and suggestions, but space limits their development. Questions remain (for example, What exactly is the negativity of human being? How is it significantly different from the aporetic self?), but the book gives the reader faith that succeeding work could address issues raised in this final chapter in the detailed manner of the preceding chapters.

A great value of this work lies in its potential to inspire further reflection on how to live wisely. The conception of selfhood articulated here suggests particular practices and techniques to know oneself and achieve integrity (hinted at in the especially compelling sections "Narrative and Dramatic Strategies of Sustaining Self-Integrity" and "Dramatic Hermeneutics"). I could imagine further inquiry pursued through a re-reading of Santayana's The Last Puritan as a dramatization of selfhood or through development of Santayana's idea of "auscultation of the psyche" (RB 335) and detailed practices of spirituality.

Kremplewska's smart and thoughtful book is both demanding and exciting to read. The book expresses a strong and inspiring interpretive vision and conveys a quiet and convincing confidence backed by admirable scholarship. There is not a lack of structure and consistent terminology, but a reader might imagine a more explicit guide through the development of ideas; repetitions and digressions might more directly illuminate the main themes. The distinctive voice and well- 
grounded understanding evidenced in the work suggest these things may well work out as a matter of course in what will surely be further valuable work in Santayana scholarship.

\section{MARTIN COLEMAN}

Indiana University Purdue University Indianapolis

\section{References}

Kremplewska , Katarzyna. 2019. Life as Insinuation: George Santayana's Hermeneutics of Finite Life and Human Self. Albany, NY: SUNY Press.,.

Santayana, George

MARG 2011. George Santayana's Marginalia: Critical edition.

RB 1942. Realms of Being. One-volume edition. New York: Charles

Scribner's Sons. 